\title{
DIFFERENCES IN HUMAN MILK (HM) CONSUMPTION BASED ON DISCHARGE DIET DURING NICU HOSPITALIZATION OF VERY LOW BIRTH WEIGHT (VLBW) INFANTS
}

\author{
H. Bigger ${ }^{1}$, L. Fogg 2 , J. Engstrom², P. Meier ${ }^{2}$ \\ ${ }^{1}$ Pediatrics, ${ }^{2}$ School of Nursing, Rush University Medical Center, Chicago, IL, USA
}

Background/aims: One difficulty in improving HM feeding is identifying patients at risk for HM feeding failure. No previous prospective study has examined the relationship between discharge diet and HM consumption during hospitalization. This study examines how discharge diet relates to early and average daily dose of HM in VLBW infants.

Methods: Data are from an ongoing 5-year prospective NIH-funded study. Informed consent obtained. Infants dying before discharge were excluded. Discharge diet was categorized as only HM, any HM, and no HM.

Results: The analysis used 194 infants. The distribution of subjects by discharge diet, average dose of HM on day of discharge, day 14 of life, and average daily dose of HM are shown. Differences between groups for average dose of HM on day of discharge and Average Daily Dose of HM during hospitalizaiton were statistically significant (ANOVA $\mathrm{p}=0.000$ ). For day 14 of life, only the no HM group was different $(\mathrm{p}=0.000)$.

\begin{tabular}{|l|c|c|c|}
\hline $\begin{array}{l}\text { Discharge diet number } \\
\text { (percent) }\end{array}$ & $\begin{array}{l}\text { Average dose of HM on } \\
\text { day of discharge }(\mathrm{ml} / \mathrm{kg})\end{array}$ & $\begin{array}{l}\text { Average dose of HM on } \\
\text { day 14 of life }(\mathrm{ml} / \mathrm{kg})\end{array}$ & $\begin{array}{l}\text { Average daily dose of } \\
\text { HM during hospitalization } \\
\text { (ml/kg/day) }\end{array}$ \\
\hline only HM 48 (25\%) & 164 & 93 & 111 \\
\hline any HM 29 (15\%) & 80 & 82 & 95 \\
\hline no HM 117 (60\%) & 0 & 48 & 34 \\
\hline
\end{tabular}

[Table]

Conclusion: Discharge diet categories correlated with the average daily dose of HM during the hospitalization of VLBW infants, but only the no HM group did at 14 days of life. Consumption of less than $50 \mathrm{ml} / \mathrm{kg} /$ day of HM early during the hospitalization may identify patients where intervention might improve HM maintenance through discharge. 